\title{
El valle calchaquí tucumano a fines del siglo XIX. Apuntes sobre el contexto productivo y las condiciones de existencia de los sectores indígenas subalternos
}

\begin{abstract}
The Calchaquí valley of Tucumán at the end of the 19th century. Notes on the productive context and the conditions of existence of the subaltern indigenous sectors
\end{abstract}

Sandra Tolosa

CONICET - Universidad Nacional de San Martín, Argentina

cahsandra@gmail.com

\begin{abstract}
RESUMEN:
En este artículo se revisan las condiciones de existencia de los sectores subalternos, en los valles Calchaquíes tucumanos a fin del siglo XIX, partiendo de la hipótesis de que esos sujetos son quienes los actuales comuneros reconocen como antepasados indígenas, pese a su condición étnica invisibilizada. Para ello se recuperan discursos sobre las condiciones productivas en tres fuentes provinciales; se reponen estudios sobre las formas de propiedad existentes y se analizan las actividades locales con datos censales de $1869 \mathrm{y}$ 1895. Retomando algunas consideraciones sobre la relación entre las categorías peón e indio, se concluye que es posible establecer vínculos entre lo analizado y los relatos actuales.
\end{abstract}

Palabras Clave: Condiciones productivas, Propiedad, Sectores subalternos, Tucumán, Valle Calchaquí.

\section{Abstract:}

In this article I review the conditions of existence of the subalternized sectors, in the Calchaqui valleys of Tucuman at the end of the 19th century, based on the hypothesis that these subjects are what the current community members recognize as indigenous ancestors, despite their invisible ethnic status. For this I recover speeches about the productive conditions in three provincial sources; I review studies on existing forms of ownership and analyze local activities with census data from 1869 and 1895. Returning to some considerations about the relationship between the pawn and Indian categories, I conclude that it is possible to establish links between the analyzed and current accounts.

KEYWORDS: Productive conditions, Property, Subaltern, Indigenous, Tucumán, Valle Calchaquí.

\section{INTRODUCCIÓN}

En este artículo planteo un acercamiento a las condiciones productivas y de existencia en el sector tucumano de los valles calchaquíes durante el último cuarto del siglo XIX, con el fin de reconstruir aspectos del contexto de los sectores subalternizados en esa zona. Este trabajo es parte de una investigación más amplia que intenta indagar, desde una perspectiva antropológica, la historia larga de la actual Comunidad India Quilmes (CIQ).

Sus miembros viven en distintas localidades (a la vez comunidades de base: El Paso, El Bañado, Los Chañares, Anjuana, Anchillos, Colalao del Valle, Quilmes Centro, Rincón de Quilmes, Las Cañas, El Pichao, El Arbolar, Talapazo, Quilmes Bajo y El Carmen) y comparten trayectorias de circulación económica, social, parental y cultural en un amplio espacio territorial que consideran propio (Ver mapa 1). No obstante, luego de las Guerras Calchaquíes y la desnaturalización de las parcialidades indígenas locales en el siglo XVII (Boixadós, 2011; Carlón, 2007; Giudicelli, 2007; Lorandi, 2000; Lorandi y Boixadós, 1987-88; Palermo y Boixadós, 1991; Palomeque, 2000; Rodríguez, 2008a; entre otros) el territorio fue repartido y los indios (especialmente los quilmes) fueron considerados extintos. La CIQ refuta dicha extinción y reclama por sus derechos territoriales, aduciendo su preexistencia en la zona y la ratificación dada por una Cédula Real de 1716 que devolvió parte del territorio a Francisco Chapurfe (cacique de los pueblos de El Bañado, Quilmes, San Francisco, Tiopunco, Encalilla y Amaicha) y a 36 indios que lo 
acompañaban. Dicha Cédula sirvió para que los Amaichas recuperaran un sector de esas tierras, mientras que otro fue apropiado. La CIQ sostiene que los límites consignados en la Cédula eran más amplios que los efectivamente devueltos y que no se respetó a todos los pueblos que el cacique Chapurfe representaba y que se mencionan en el documento. Sumado a esto, otros procesos históricos específicos, en un territorio relativamente pequeño, definieron situaciones distintas respecto de la tierra, y por lo tanto de las relaciones sociales.

Además de la expropiación, la CIQ denuncia una situación histórica de explotación para su pueblo, a manos de quienes se adueñaron del territorio, en un sistema que denominan "terratenientismo": un tipo de explotación basada en el arriendo, pago de cánones (yerbaje, aguas, proporción de producción) y obligaciones de trabajo en las fincas de los patrones. Estos además ocuparon históricamente funciones públicas, especialmente las de policía y justicia -impidiendo el reclamo de los sectores bajos- y las de educación, que según los comuneros, colaboraron con la ruptura de sus tradiciones indígenas.

Estas distintas aristas plantean la necesidad de revisar los procesos históricos que devienen en formas y condiciones de existencia específicas, haciendo foco en aquellos sectores subalternizados que los actuales comuneros reconocen como sus antepasados. Con este fin y centrándome en las últimas décadas del siglo XIX, comenzaré planteando las condiciones productivas de la zona desde la perspectiva de tres fuentes publicadas en la provincia en 1872, 1883 y 1916, cuyo entrecruzamiento permite ver un cambio de enfoque, desde un inicial desinterés a una creciente atención en su potencialidad. Luego, expondré algunas líneas que permitan comprender la diversidad de los procesos y formas de propiedad existentes entonces en el distrito. Posteriormente, plantearé un acercamiento a las posiciones de los sujetos subalternos en la estructura económico-política local, a partir de la revisión de sus actividades en los censos de 1869 y 1895 , ya que no poseen voz propia en las fuentes de la época. Por último, retomaré en las conclusiones algunas consideraciones sobre la relación entre la categoría laboral de peón y la de indio en escritos de investigadores de la época. 
FIGURA 1

Ubicación del área de los valles calchaquíes tucumanos, provincia de Tucumán

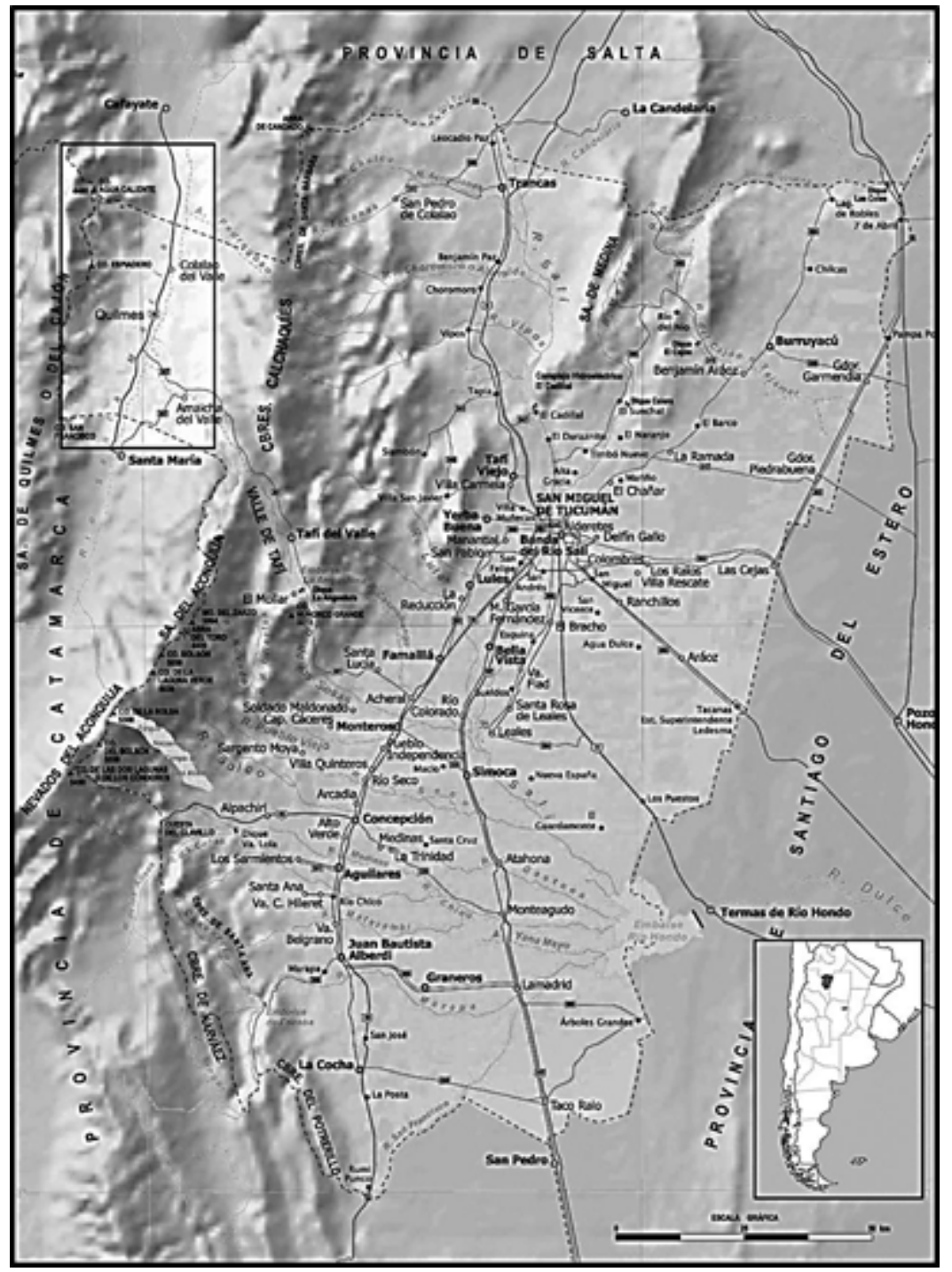

Fuente: Instituto Geográfico Nacional, elaboración propia.

\section{EL SECTOR MONTAÑOSO EN LAS PUBLICACIONES PROVINCIALES}

Para 1870, con los límites provinciales definidos (Frías \& Posse, 1863, citado en Granillo, 1872, p. 32-33) la división político-administrativa de la provincia era de diez departamentos, subdivididos en dos distritos de campaña y estos en secciones. Cada departamento se regía por un Comandante militar; dos Jueces de Paz o de Distrito; un Juez Departamental o de Aplicación y dos vocales para sentencias difíciles; y Comisarios de campaña que dependían de la Jefatura capital. En 1870 el sector que nos ocupa se denominaba Encalilla y contaba con dos subdistritos (Tafí y Colalao), cada uno con su iglesia y un pequeño caserío (Censo Nacional, 1869, p. 488). Para fin del XIX, todo el departamento pasó a denominarse Tafí, dividiéndose según las laderas del Aconquija en Tafí I (Los Cainzos, Cebil Redondo, Raco, Yerba Buena, Tafí Viejo, Rastrojo y Siambón), y Tafí II (Tafí del Valle, Amaicha y Colalao -rural y urbano-) (Censo Nacional, 1895, p. 524).

¿Cómo se percibía y describía en la época este sector "montañoso" de la provincia? Para acercarnos a esta perspectiva, tomaré las descripciones de tres importantes publicaciones, realizadas en 1872, 1882 y, 
finalmente, 1916. Debe tenerse en cuenta que estas obras fueron producidas desde la capital, punto neurálgico del poder político y del crecimiento económico de la industria azucarera comenzado en 1870.

\section{a) Arsenio Granillo}

Tucumán fomentó (siguiendo los ideales de progreso de la nación) el estudio y difusión de sus elementos productivos y sus riquezas, ya que "para atraer la inmigración es necesario hacer conocer al estrangero los provechos que puede sacar." (Gordillo citado en Granillo 1872, p. 15). En este sentido, las Memorias Descriptivas y las Exposiciones fueron instrumentos diseñados para dar a conocer las riquezas de cada provincia. Por ello, con el objetivo de abrir Tucumán al mercado, el gobernador Federico Helguera encargó al jurista Arsenio Granillo una Memoria para ser presentada en la Exposición Nacional de Córdoba de 1871, que resultó en la publicación de Provincia de Tucumán. Serie de artículos descriptivos y noticiosos (1872). La obra registró datos históricos, aspectos físicos, climáticos, recursos naturales y productivos, manufacturas, cifras de gasto público y descripciones de su sociedad de "tipo indígena bastante modificado por las cruzas de las razas europeas" (Granillo, 1872, pp. 44-45), acompañados novedosamente por fotografías tomadas por el italianongel Paganelli.

En esta obra, el sector montañoso aparece como una zona productivamente marginal, en contraste con el llano, centro político y económico regional. Las amigables descripciones sobre el "Jardín de la República" no traspasaban el cordón del Aconquija. Granillo (1872), que exponía detalladamente las bondades provinciales -especialmente del Departamento de Capital-, casi no mencionaba a la serranía, ni siquiera en el apartado "Pueblos de campaña". Sí se incluía, al final, un texto romántico de Lucas Córdoba sobre Tafí (en Granillo, 1872, pp. 157-160) donde la descripción de un paisaje "natural" indómito era caracterizado por la ausencia humana, sólo enunciada en una vidalita entonada por un gaucho y en el recuerdo del pasado calchaquí emanando de sus ruinas.

Este desinterés puede vincularse con un momento inicial en la centralización de recursos económicos y políticos en el área oriental y la consecuente marginación del occidental. Hasta el momento, las producciones e industrias del llano eran variadas. Aunque las primeras eran el azúcar y el aguardiente, eran importantes los cultivos de trigo, maíz y tabaco; frutales (naranjos, limones, limas y cidras), los aserraderos de madera que explotaban árboles nativos, la fabricación de ladrillo, los molinos harineros, las curtiembres. Además se producían manufacturas como tejidos, talabartería, calzado, carpintería, cigarros. Luego del fomento a la integración económica impulsado durante la presidencia de Mitre (1862-1868), los sectores pudientes de la sociedad tucumana reorientaron sus inversiones hacia el azúcar (Sánchez Román, 2008; Campi, 1996).

La somera descripción sobre Tafí, en términos productivos, se reducía a la cría de ganado, especialmente lanar que proveía a la industria pellonera (poco abundante en el resto de la provincia), y a la industria de quesos, traída por los jesuitas y considerada un ramo importante de la ganadería, ya que exportaba unas 12.000 arrobas anuales al Litoral, Buenos Aires y países vecinos (Granillo, 1872, p. 104). Tafí era asociado así a la cría de animales de pastoreo, rama distinta de la cría de ganado vacuno en el llano, que Granillo consideraba una de las industrias más productivas de la provincia.

Pero pongamos en relación lo antedicho con las reflexiones del autor sobre el progreso de la provincia (es decir la ciudad y la campaña que la rodeaba) que, según sus palabras, se debía enteramente a la agricultura, ya que Tucumán, entregada casi en su totalidad al cultivo de la tierra, había logrado aventajar en civilización y desarrollo material de la población a los "pueblos pastores" que la rodeaban. El agricultor aparece como modelo de un esfuerzo que calma las pasiones y que alimenta a su familia con "los frutos ó las flores con las que Dios bendjiera su trabajo" (Granillo, 1872, p. 130), en contraste con el pastor, endurecido por la lucha que le demandan los animales. Los trabajos modelarían los caracteres de ambos: mientras el labrador es "manso, suave, afable, comunicativo, hospitalario: el pastor es irascible, áspero terco, esquivo hasta el arbitrario". (Granillo, 1872, p. 130) 
Para Granillo estas circunstancias, aplicadas a las masas de los pueblos, determinaban su grado de atraso o civilización. La fundamentación política del autor aparece siguiendo la cadena lógica del discurso. El pastoreo reduce a estos pueblos a una especie de limbo barbárico: “como los guerreros, pueden alguna vez deslumbrar al mundo con sus triunfos en el terreno en que impera la fuerza bruta, pero sus glorias no son sino resplandores siniestros que iluminan catástrofes y sangre." (Granillo, 1872, p. 131). El razonamiento concluye con la descripción del caudillaje como el "ejemplo palpitante e la influencia perniciosa del pastoreo en la vida y destino de los pueblos" (Granillo, 1872, p. 132) sobre el que había triunfado el proceso de Organización Nacional y la propiedad privada de la tierra, único medio para hacer desaparecer el salvajismo y contener al "gaucho nómade en sus instintos vagabundos", de acuerdo con Avellaneda (1865). Por todo esto, el "mejoramiento social” de Tucumán se debía enteramente a esa

ocupación honesta y lucrativa á las masas de la campaña, que ha influido poderosamente para suavizar su carácter y mejorar sus usos y costumbres. En Tucumán han desaparecido ciertos tipos, enjendros de la vagancia y el pastoreo, que forman el fondo del cuadro que en otras provincias ofrecen sus poblaciones campesinas. En lugar del gaucho nómade, se encuentra al propietario arraigado que, multiplicando su haber con el trabajo constante, se ha creado goces y necesidades de vida civilizada (Granillo, 1872, p. 45).

Esta promisoria descripción de una provincia agricultora, "civilizada" y propietaria era sumamente parcial, lo que es comprensible en un texto orientado a atraer inmigrantes. Además, se limitaba al llano donde, según el autor, el empobrecimiento de los grandes propietarios durante la guerra había fraccionado la tierra de tal modo que casi todas las familias eran dueñas de alguna parcela cultivable y casi no existía el sistema de arriendo. Esto también contrastaba con el sector serrano, donde en 1874 sólo se contabilizaban 27 propietarios y propiedades, en una población censada de 1463 personas. Tampoco incluía a los sectores sin propiedad del llano, aunque se reconocía la existencia de un sector castigado, causado por la guerra en décadas anteriores: "una última capa social de la cual poco caso se ha hecho y por consecuencia tiende hacia la barbarie, y quiere retroceder hacia aquellos tiempos calamitosos, en que la riqueza particular no tenía garantía ni la vida del ciudadano seguridad" (Alcalde Espejo, citado en Granillo, 1872, p. 187).

La apuesta de Granillo a la agricultura parece haber sido exitosa si se mide desde la velocidad del avance azucarero en esa década. Los empresarios locales instalaron ingenios en el área fértil (especialmente Cruz Alta y la banda derecha del río Salí), reforzando la importancia de la capital como centro político y financiero. El cambio radical se produjo con la inauguración del Ferrocarril en 1876. Hasta allí, el transporte de tracción a sangre limitaba la circulación de los productos a espacios limítrofes y el equipamiento y métodos de elaboración de las fábricas eran obsoletos. Con la llegada del riel y la ayuda de políticas crediticias comenzó a importarse maquinaria, desaparecieron los trapiches de madera y se ingresó a la era del vapor.

\section{b) Paul Groussac}

A pesar de la obra de Granillo, la inmigración europea no influyó sensiblemente en el movimiento poblacional de Tucumán en estos años (Groussac, Bousquet, Liberani, Terán, y Frías, 1882, p. 272). El esfuerzo se retomó en la década siguiente, cuando el gobernador Miguel Nougués encargó una obra similar a Paul Groussac, Juan Manuel Terán, Javier F. Frías, Inocencio Liberani y Alfredo Bousquet, siguiendo el pedido del gobierno nacional a las provincias para que expusieran su potencial productivo en memorias descriptivas, de cara a la Exposición Continental de 1882. Esta Memoria histórica y descriptiva de la Provincia de Tucumán (1882) cuenta con una base de documentos, cifras y datos estadísticos mayor que la anterior y fue premiada por el jurado de la Exposición. Groussac, quien vivió en Tucumán entre 1871 y 1882, redactó seis capítulos históricos para la primera parte y cinco de la segunda, destinados a aspectos geográficos; al mismo tiempo, publicó ese material en su Ensayo Histórico sobre el Tucumán. Estas obras le dieron renombre y le abrieron camino a una carrera en el ámbito de la cultura y la educación (Bruno, 2017). 
Para ese momento el capital invertido en maquinaria sumaba $\$ 1.441 .000$; las fábricas potenciaron su fuerza motriz con una centena de motores a vapor e hidráulicos (Girbal-Blacha, 1991). El crecimiento del sector atravesó rápidamente los estrechos circuitos de comercialización tradicionales y logró instalarse en un mercado interno en expansión (Lagos, 1992). Hasta allí el azúcar tucumano no lograba competir con el importado de Cuba (Groussac et al., 1882, p. 289) pero el acceso al mercado internacional fue fomentado por políticas proteccionistas y aranceles aduaneros diferenciales, frente al aumento de las tasas de ingreso de azúcar importado, que lo volvió incompetente (Rutledge, 1987). Entre 1877 y 1881 se duplicaron las hectáreas cultivadas y nacieron nuevos pueblos e ingenios alrededor de las líneas troncales y secundarias del ferrocarril en el llano.

Frente a esto, el extenso, "fragroso y quebrado" terreno de la montaña continuaba siendo el menos poblado y productivo de la provincia. Groussac reconocía sin embargo una serie de recursos minerales que no habían sido detallados por Granillo, quien mencionaba someramente la existencia de oro, plata, cobre, plomo, fierro, cristal de roca, mármoles y cal en las sierras de Aconquija. Ahora se destacaba una abundante calera en Tafí, "estaño (nativo), cobre (id), piritas de cobre y de hierro, sulfuro de mercurio (cinabrio), kaolin y otros muchos minerales que revelan futuros aumentos de riqueza industrial para esta Provincia" (Groussac et al., 1882, p. 284). En esa época, otros trabajos confirmaron la existencia de laboreos de minas e instrumentos de metal prehispánicos en la zona (Hoskold, 1889; Lafone Quevedo, 1888, 1894; Quiroga, 1926; Moreno,1901, citado en Ambrosetti, 1904). Pero los escritos también referían a la falta de explotación sistemática y de hombres competentes, salvo excepciones como el ingenio de Samuel Fisher Lafone que había explotado los minerales de Capillitas y en 1862 se había trasladado al sur catamarqueño, luego de haber consumido los algarrobales de la zona.

Groussac continuaba destacando la importancia de la cría de animales de carga, cabras y ganado lanar, ahora también en relación al comercio, junto con la manufactura de pellones y la industria quesera. Pero respecto de la actividad agrícola (inexistente para Granillo) describía pequeñas producciones de maíz, trigo y cebada en Encalilla y Colalao y el crecimiento del cultivo de alfalfa en toda la zona, para la invernada de los potreros de Tafí. También mencionaba ensayos con papa, batata, maní y mandioca en Colalao y Tafí y con lino y alpiste en la estancia de Clemente Zavaleta (Groussac et al., 1882, pp. 406-423), aunque planteaba como problema que era el único lugar de la provincia que no cultivaba maíz (base de la dieta de los peones), y que debía trasladarse desde la capital o Monteros, con un alto costo por los difíciles caminos.

Un punto que comenzaba a señalarse aquí era la virtud de los suelos de Colalao y Amaicha para el cultivo de la vid (actualmente una de las principales inversiones de la zona). Hasta allí, sólo quedaban las ruinas de los establecimientos vinícolas jesuitas y un único viñedo activo, el de Felipe Tanco. Ante una superficie cultivable de $200 \mathrm{~km} 2$ y bajo costo de producción, se sugería modernizar las técnicas para evitar desperdicios y mejorar la calidad y se pedía al gobierno protección y propagación de conocimientos sobre esa industria "aún en embrión en la República pero que sin duda llegará a constituir una fuente de riqueza para el país entero" (Groussac et al., 1882, pp. 457-461). Así, a través de una narrativa de la potencialidad, se comenzaba a visibilizar una zona hasta allí excluida de la inversión de capitales, ya casi exclusivamente dirigidos al sector cañero. Años después, Ambrosetti (1895) confirmaba la tendencia hacia la industria vinícola en los vecinos poblados salteños de Cafayate y Tolombón, elogiando sus posibilidades y sugiriendo la necesidad de modernizar el proceso y el riego, además de solucionar el problema del camino a Tucumán, que limitaba el comercio sólo a Salta.

Quiero sumar aquí, a modo de ejemplo, otro tipo de documento de principios del siglo XX que destacaba la potencialidad de la zona. Me refiero a la Memoria de la finca de El Bañado, confeccionada en 1911 por un agrimensor comisionado para su venta, donde se ponderaban las capacidades productivas de la propiedad, posiblemente aumentadas con el objeto de valorizarla. La finca contaba con una superficie de labranza o "pan llevar" de 7.000 ha que, aunque irregable, podría abastecerse de aguas a través de trabajos de embalse de sus arroyos y vertientes en Anjuana, Tala Paso, Quebrada de Las Cañas y Quebrada de Quilmes. De las pocas hectáreas cultivadas, se especifican 35 con alfalfa, 70 de maíz y 20 de otros productos. También se describe 
su riqueza forestal, variada fauna, la posibilidad de industrializar los cultivos de trigo, maíz, cebada y alfalfa; papas, batatas y maní; frutales (durazno, higos y membrillos); ganado ovino, vacuno y equino. Nuevamente:

La vid, ocupa el primer lugar dentro de las plantas cultivadas en la región, conocidos son los productos de Santa María y Cafayate. Las condiciones del clima y composición física del suelo los hace inmejorables (...) semejante a los que en Francia se utilizan. Esperando un mejoramiento científico industrial de la forma y manera de efectuarlos; (...) produce por hectárea 70 a 90 cargas de vino. La carga son dos barriles de 50 litros cada uno. (...) Los cepajes que se cultivan allí son: la negra criolla, uva huevo de gallo, rubia primera torrentel, moscatel blanca y negra. En Colalao del Valle se cultiva próximamente una extensión de 25 hectáreas. ${ }^{1}$

El aumento de atención sobre las posibilidades productivas de la zona montañosa parece ampliarse así con el paso del tiempo. Ahora bien, este avance puede ser resignificado si se vincula con la problemática que comenzaba a plantear el monocultivo cañero en la provincia.

\section{c) El Álbum del Centenario}

Para explicar esto, tomaremos como referencia el Álbum General de la Provincia de Tucumán. Primer Centenario de la Independencia Argentina. 1816-1916. Publicado en 1916, años después del despegue y del vertiginoso avance de la industria azucarera, se trataba de un volumen de conmemoración del Centenario de la Independencia. De gran formato, con fotos, ilustraciones y láminas a color, fue compilado por Domingo Villarrubia Norry y editado por la Comisión Oficial del Centenario, que presidía el empresario azucarero Eudoro Avellaneda y contaba con políticos, industriales, intelectuales y comerciantes tucumanos destacados. Su amplio recorrido histórico va desde el periodo prehispánico hasta el mismo Centenario, con capítulos enteros dedicados a hechos de importancia. También contiene descripciones sobre geografía, geología economía, educación, artes, arqueología, religión, universidad, milicia, comercio y homenajes a personalidades provinciales. Pero el punto que nos interesa es un texto en el que la inducción a la inversión de hombres emprendedores en la zona se acompañaba de una crítica hacia la industria azucarera, pese a que la misma Comisión del Centenario estaba ligada a los intereses del sector.

Hoy puede decirse que todo el interés de los pobladores se resume en el cultivo de la caña y de la industria azucarera. Alrededor
de las chimeneas se encuentra la población y ellas condensan todas las esperanzas, obscureciendo con su sombra otros campos
de utilidad quizás más provechosos (...) su despótica absorción de todas las energías constituye indudablemente un gravísimo
peligro, en una comarca que no está enteramente libre de inconvenientes para su desarrollo. Y así la vemos siempre presa
de alarmas producidas unas veces porque la superproducción plantea un problema casi insoluble y otras porque heladas
prematuras o tardías, lluvias escasas o inoportunas reducen el rendimiento a cifras que llevan a situaciones angustiosas a
los cultivadores y provocan en el resto del país protestas por el encarecimiento del artículo, renovando la vieja cuestión del
proteccionismo y sus inconvenientes ante las necesidades de las industrias cerealista y ganadera que quisieran implantar en
el país el régimen del libre cambio (Álbum General, 1916, s/p).

Comenzaba así a manifestarse preocupación sobre el impacto de los vaivenes de la industria en la economía provincial, que afectaba la renta pública, el valor de la propiedad, los precios, los niveles de pobreza, ${ }^{2}$ la desaparición de la pequeña propiedad y el "ensanchamiento" de los latifundios; aunque se ha indicado que el proceso no implicó concentración de tierras (a diferencia del modelo jujeño) por los tempranos procesos de extrema subdivisión de la tierra y por la ausencia de tierras públicas (Balán, 1976).

Sí se ha estudiado la gran concentración demográfica en el llano, el alto grado de mercantilización de la población, la convivencia entre pequeños y medianos productores -cañeros independientes, campesinos minifundistas- y los dueños de los ingenios; y también la rápida proletarización de los campesinos de la zona, todos dedicados a la industria, que a inicios de siglo cubría el 85,5 \% de la producción nacional. El Censo de 1895 indica que la superficie cañera había aumentado, desde 1875, de 2.045 a 54.233 ha. En cuanto al mercado de trabajo, la escasez de mano de obra local produjo el asalariamiento de sus propios campesinos y la 
migración de trabajadores de zonas satélites a la capital y de provincias vecinas como Santiago y Catamarca, sobre todo durante la cosecha, proceso que supuso el estancamiento económico y demográfico de esas áreas dependientes del azúcar. La adaptación al régimen de la plantación fue difícil para quienes provenían de sistemas libres de agricultura, por lo que la cooptación de mano de obra combinó el pago de salario y el uso de métodos coactivos como leyes de conchabos, vagancia, peonaje por deudas (Campi, 1991; Campi y Lagos, 1995, entre otros).

Así, a 30 años del despegue azucarero, el rigor de las fluctuaciones del mercado y los efectos de la dependencia del monocultivo industrial que había acaparado todas las inversiones, la mano de obra y la tierra, comenzaba a sentirse, y la búsqueda de otros sectores productivos era planteada como posibilidades para la reorientación del capital.

En esa línea, el Álbum menciona otros posibles cultivos, como el de legumbres en la Quebrada de Lules. Respecto del Oeste, continuaba destacando la actividad ganadera de Tafí, aunque ahora con mayor énfasis en las posibilidades de la industria lechera. Pero aunque se seguía manteniendo la caracterización antagónica entre un Este, "de ensueño donde la naturaleza despliega sus mejores galas en los infinitos matices de una policromía maravillosa", y un Oeste "de aspecto desolado, de clima rudo y bordeado de montañas en cuyos flancos desnudos y ásperos enredan sus salvajes sinfonías los huracanes" (1916, s/p), se diferenciaban dos sectores a cada margen del río Santa María. De un lado, un paisaje "desierto”, sólo habitado por cardones:

las llanuras del Sahara no han de ofrecer aspecto más ingrato y triste que estas tierras en declive: aridez y soledad por todos lados, y al frente el lecho del rio Santa María, rio temporario, especie de oasis africano (...) Sus tierras pobres, mezcla de pedregullo y caliza y su casi absoluta falta de agua, hacen imposible toda explotación agrícola o ganadera. (Álbum General, $1916, \mathrm{~s} / \mathrm{p})$.

Del otro lado (margen occidental hacia las cumbres de Quilmes) la situación mejoraba. Una mayor conservación de humedad y la conformación química del suelo explicaban científicamente la fecundidad de los cultivos de olivo y frutales. Ya se vislumbraba el aumento de productividad de la alfalfa y de los viñedos de cepa española, que podrían fortalecerse como industria con un mayor financiamiento que permitiera a los bodegueros estacionar el vino. La zona se presentaba además como "refugio agradable y cómodo donde restaurar las fuerzas debilitadas por la actividad intensa de la Capital y de las fábricas de azúcar”, y aunque todo estaba por hacerse y la falta de una vía férrea era "un grave inconveniente que coloca a esta comarca en una situación desventajosa para luchar con la competencia de otras dotadas de ese elemento de comunicación”, ofrecía un ancho campo a hombres emprendedores y con capital (Álbum General, 1916, s/p).

Estos datos generales se pueden contrastar con los que brinda el Segundo Censo Nacional (1895) que corroboran el aumento de productividad en Tafí I y II (contabilizados en conjunto) que se corresponde a su vez con un importante aumento poblacional respecto de 1869 . No obstante, puede verse que la actividad más importante continuaba siendo la ganadera. 
TABLA 1

Producciones agrícolas en Tafí II

\begin{tabular}{|c|c|c|}
\hline \multicolumn{3}{|c|}{ Producciones agricolas Tafi II } \\
\hline \multicolumn{2}{|c|}{ Tpo de cultivo } & \multirow{2}{*}{$\begin{array}{c}\text { Hectáreas } \\
\text { cultivadas } \\
379\end{array}$} \\
\hline Cereales & Trigo & \\
\hline & Maź & 431 \\
\hline & Lino & - \\
\hline & Cebada & 11 \\
\hline \multirow{5}{*}{$\begin{array}{c}\text { Plantas } \\
\text { industriales }\end{array}$} & Algodón & - \\
\hline & Mani & - \\
\hline & Caña & - \\
\hline & Tabaco & - \\
\hline & Viña & 260 \\
\hline \multirow{3}{*}{ Legumbres } & Papas & - \\
\hline & Porotos & - \\
\hline & Otras & - \\
\hline Forrajeras & Alfalfa & 271 \\
\hline Árboles & $\begin{array}{l}\text { Frutales } \\
\text { Forestales } \\
\text { Ornamento }\end{array}$ & $\begin{array}{l}5 \\
4 \\
3\end{array}$ \\
\hline
\end{tabular}

TABLA 2

Ganadería en Tafí I y II

\begin{tabular}{|c|c|c|c|}
\hline \multicolumn{4}{|c|}{ Ganadería en Tafi l y II para 1895} \\
\hline Tipo de ganado & produ & $\begin{array}{l}\text { ar en la } \\
\text { on provincial }\end{array}$ & Total de cabezas \\
\hline \multirow{3}{*}{ Vacuno } & $1^{\circ}$ & Bumuyacú & 83.412 \\
\hline & $2^{\circ}$ & Tafi & 60.019 \\
\hline & $3^{\circ}$ & Chicligasta & 42.730 \\
\hline \multirow{3}{*}{$\begin{array}{l}\text { Caballar, } \\
\text { Burros yMulas }\end{array}$} & $1^{\circ}$ & CruzAta & 17.139 \\
\hline & $2^{\circ}$ & Tafi & 12.690 \\
\hline & $3^{\circ}$ & Chicligasta & 12.497 \\
\hline \multirow{3}{*}{ Lanar } & $1^{\circ}$ & Tafi & 31.097 \\
\hline & $2^{\circ}$ & Chicligasta & 13.995 \\
\hline & $3^{\circ}$ & Leales & 13.512 \\
\hline \multirow{3}{*}{ Cabrio } & $1^{\circ}$ & Tafi & 16.100 \\
\hline & $2^{\circ}$ & Graneros & 15.565 \\
\hline & $3^{*}$ & Leales & 8.891 \\
\hline
\end{tabular}

Fuente: Elaboración propia a partir de los datos del Censo Nacional de 1895. AGN, Censo Nacional de 1895, Censos Complementarios)

Fuente: Elaboración propia a partir de los datos del Censo Nacional de 1895. AGN, Censo Nacional de 1895, Censos Complementarios) 
La primera tabla especifica los cultivos, corroborando el aumento señalado en la alfalfa y evidenciando a la vez poca variedad de otros cultivos. Respecto de los viñedos, las cifras indican algo interesante: mientras que Tafí ocupa el primer lugar en el número de propiedades destinadas a este fin (18) estas son de superficies menores a las de Trancas y Graneros, que lo superan. Sin embargo, su valor es muy superior: mientras que las 286 ha en Tafí están valuadas en $\$ 30.415$, las 406 ha de Trancas lo están en $\$ 16.000$ y las 300 ha de Graneros en sólo $\$ 4.000$ (Censo Nacional 1895, Tomo III, p. 185). También hay que destacar que las únicas 4 fábricas de vino de uva de la provincia se ubican en Tafí, con una producción de $203 \mathrm{hl}$ de vino y mano de obra de 54 personas en temporada. Sin embargo, estos números son muy inferiores a la producción de la cercana localidad de Cafayate (Salta) que contaba con 22 fábricas, producía 11.002 hl y ocupaba a 442 personas. (Censo Nacional 1895, Tomo III, pp. 327 y 330).

La segunda tabla demuestra la continuidad e importancia de la ganadería en este distrito, que lo coloca en el primer y segundo puesto en la producción provincial. Con respecto a otros animales, sin embargo, Tafí ocupa los últimos puestos; por ejemplo, en la cría de ganado porcino (1.458 cabezas contra 7.079 de Monteros, 4.709 de Chicligasta, 4.694 de Famaillá). Respecto de la cría de aves de corral (especialmente gallinas) las mínimas cifras señalan que se orienta al consumo familiar.

\section{Propiedad de la tierRa}

Planteadas las características productivas, en este apartado revisaré cómo distintos desarrollos históricos ocurridos en el distrito de Tafí dieron como resultado la formación de núcleos poblacionales, formas de propiedad y relaciones sociales diversas. En este sentido, el valle de Tafí (I) y sus contiguos eran parte de las posesiones de los jesuitas que habían instalado las primeras "salas" de estancias a su llegada en 1718. Luego de la expulsión de la Orden y la venta de sus bienes en 1767 se inició un proceso de urbanización que se desarrolló muy lentamente por la perduración de los latifundios de allí surgidos. ${ }^{3}$ A fin del siglo XIX, seguían existiendo pocas estancias, dedicadas al ganado lanar y vacuno y a la producción de quesos. A la vez, la zona comenzaba a ser destino de veraneo de las familias de élite de la ciudad, atraídas por su fresco clima (Groussac et al., 1882), aunque las dificultades de acceso no permitieron que el destino fuera masivo sino hasta mediados del siglo XX.

Pasando el Abra del Infiernillo hacia el Oeste, en la zona que nos ocupa, Amaicha plantea un caso singular de reconocimiento de derechos territoriales indígenas. Originalmente ubicado en el camino de tambos incas que iban desde la puna jujeña hasta Londres y luego a Chile -camino que siguió Almagro en 1536- Amaicha pudo haber sido un apeadero entre Colalao y Tafí. Posteriormente, el viejo camino que pasaba por el pueblo fue usado por los jesuitas para el comercio de bueyes y mulas hacia Perú, y a Santa María para el laboreo de minas de Capillitas. Con las desnaturalizaciones al fin de las Guerras Calchaquíes, la población fue trasladada, formando el poblado de Amaicha del Llano en Leales. Pero la mencionada Cédula Real de 1716 permitió que los amaichas lograran recuperar parte de su territorio, sorteando exitosamente diferentes pleitos (CIQ, 2006; Figueroa Román y Mulet, 1949; Isla, 2002; Sosa, 2015 y Rodríguez, 2009).

El pueblo de Amaicha se situaba en el actual paraje de Encalilla, a $15 \mathrm{~km}$ de su ubicación actual; entre 1880 y 1890 se trasladó, fundándose la Villa de Amaicha del Valle en su locación actual (Zerda de Cainzo, 1972; Reyes Gajardo, 1965; Steiman, 2013). A partir de allí, la urbanización fue incrementándose; con la instalación de la primera escuela, y con la construcción comunitaria de la iglesia -otra iniciativa de Colombres- y el casco urbano de la villa, se desarrolló en el marco de 14 manzanas donadas a la curia, en terrenos que fueron subdividiéndose y vendiéndose. Para la primera década del siglo XX, el listado de comuneros apuntados como propietarios de Amaicha era de 50 personas. ${ }^{4}$ Pero recién en 1947 se aprobó el árbol genealógico y el padrón de descendientes directos de los 36 indios beneficiados por la Cédula. 
Hacia el Noroeste y camino a Salta, Colalao del Valle fue el resultado del proceso de división de las grandes propiedades coloniales durante el siglo XVIII, como la estancia de San Carlos, formada con mercedes otorgadas a Pedro Días de Loria e incrementada luego con las otorgadas a su hermano Domingo y con la compra posterior de tierras a Tomás Escobar de Castellanos en la Quebrada de Tolombón y a Pedro Bazán en Colalao. A comienzos del siglo XVIII la propiedad se extendía desde su casco en San Carlos hasta Quilmes y Amaicha. Posteriormente su hermano y heredero Fernando de Lispequer y Aguirre compró baldíos en los cerros. A su muerte en 1719 , la propiedad valuada en $\$ 1200$-incluyendo herramientas, viñedo, trapiche y fuerza de trabajo indígena (Reyes Gajardo, 1965, pp. 120-121)- pasó a su esposa y luego a su hija y yerno, Marcos Aramburu. En 1770 fue dividida de modo poco equitativo entre los hijos de estos, Nicolás Ignacio (mitad Norte) y María Crisóstoma (mitad Sur) (Mata, 2000, pp. 151-153 y 229).

Así, estas grandes unidades de producción fueron dividiéndose y el menor precio de estas tierras respecto de otras -como las del Valle de Lerma- permitió que nuevos actores sociales pudieran acceder al status de propietarios, por haber reunido el capital o por otras estrategias de acceso (Medina, 2002). Este proceso afectó especialmente a la propiedad comunal que indios Colalaos y Tolombones ${ }^{5}$ (a diferencia de otros pueblos de indios trasladados a otras jurisdicciones) habían podido mantener con documentos y derechos durante el siglo XVIII (Mata, 1999). En el XIX, luego de una serie de pleitos, se fue pasando del sistema comunitario a otro de explotación particular, proceso que se intensificó en la segunda mitad del siglo (López y Bascary, 1998). Entre 1877 y 1895, momento de urbanización de la villa, Fandos (2007) señala una evolución de 36 a 97 propietarios de pocas hectáreas que supera en porcentaje (60\%) a los arrendatarios. De los 45 jefes de familia originarios con usufructo, en 1895 -luego del parcelamiento de la tierra comunal-sólo quedaban 21 con propiedad privada de sus parcelas.

La estructura social de la zona se fue transformando, con la convivencia entre pequeños propietarios de explotación intensiva y otros de producción extensiva (Medina, 2002). Para fin de siglo, con su urbanización, Colalao era una de las tres sedes del distrito de Tafí II y contaba con Comisario, Juez de Paz, oficina de Correo y telégrafo. Esta modernización es simultánea a las positivas caracterizaciones de las Descripciones provinciales sobre ese espacio, propicio para la reorientación de capitales.

Por otro lado, algunas grandes fincas mantuvieron su extensión, como la de El Bañado, que pese a cambiar de dueños varias veces durante el siglo $\mathrm{XIX}^{6}$ sostuvo sus 30.130 ha hasta el siglo XX, y continuó el sistema de arriendo y el cobro de cánones y obligaciones hasta que durante el Primer Parlamento Indígena de los Valles (1973) los indígenas decidieron negarse a continuar pagando (en este y otros casos similares) por considerar que se trataba de su territorio. Ya Lafone Quevedo había señalado que los amaichas habían

pleiteado durante un siglo con los ocupantes del bañado de Quilmes, y hasta el día de hoy conservan la pretensión de reivindicar parte, sino el todo de aquella propiedad. Según los documentos, la familia de Aramburu la ocupaba con permiso de los indios Hamaichas (Lafone Quevedo, 1899, p. 124).

En 1974, un informe del Consejo Federal de Inversiones (CFI, 1974) confirmaba que la extensión otorgada en la Cédula Real era mucho mayor que la efectivamente devuelta: rondaba las 90.000 ha, llegaba hasta el límite con Salta e incluía El Bañado y otras propiedades (Tolosa, 2018 y 2019). 
Sin embargo, al momento de la mensura de la finca en 1911, todos los terrenos aledaños contaban con títulos que fueron cotejados por el agrimensor. Hacia el Norte, se mencionan las propiedades de Susano Aráoz, Cruz Aparicio, Pantaleón González, Moya hermanos, Juana F, Bravo de Aráoz, Dámaso Medina, herederos de Buenaventura Aráoz y Alejandro Vega. Hacia el Sur, la finca de El Paso, de Arturo Escobar y de Virginia Villagra de Cisneros (Los Villagra o Villagrán eran una familia de encomenderos de indios Ingamanas). También se menciona a Timoteo Ayala como propietario de las sierras al Este del río Santa María, y a la comunidad Amaicha en su ubicación actual. ${ }^{7}$

Es interesante que el único deslinde practicado anteriormente (1858) correspondía a la cesión El Pichao (parte de la estancia de Colalao) que hiciera Ángel Plaza a Pilar Aráoz, en pago de una deuda. El mismo deslinde fue ratificado en 1861, cuando Pedro Aráoz transfirió sus derechos a Doña Paula Quiroga. Esto permite ver las distintas formas de acceso a la tierra que gestionaban los sujetos. Por su parte, el límite Sud fue reconocido recién en esta mensura, en el "Campo de los Chañares", donde se practicaban corridas de hacienda. Vecinos y testigos confirmaron que era el límite entre las fincas de El Bañado y El Paso y así era respetado por arrenderos y propietarios de ambas fincas, lo que confirma que ambas propiedades sostenían ese sistema.

Los ejemplos citados permiten observar la convivencia de distintas formas, tipos y extensiones de propiedad. Esta variabilidad requiere seguir siendo indagada, ya que sus matices no se reflejan en los datos oficiales, en parte porque no todas las "propiedades" cuentan con títulos; esto se irá complejizando más aun con el correr del siglo XX.

Volviendo a la época, el Censo de 1869 no consigna propietarios; en 1874, los padrones de Contribución Directa registraban para toda Tucumán un total de 9.361 propiedades repartidas entre 7.158 propietarios, con un aumento de $60 \%$ hacia 1881. La relación entre propietario/propiedades era: para Tafí 13/13 (1874) y 10/12 (1881), para Encalilla, 1/1 (1874) en y 4/4 (1881), y para Colalao 13/13 (1874) y 17/18 (1881) (Groussac et al., 1882, p. 502). Comparado con la acelerada subdivisión del llano tucumano, la serranía se destacaba como el único sector donde prevalecían las grandes estancias, casi desaparecidas del resto de la provincia. Posteriormente, el Censo de 1895 contabiliza para Tafí II 248 "propietarios de bienes raíces" (Segundo Censo Nacional, 1895, Tomo II, p. 547), aunque no se indica si ese valor surge de la simple consulta censal o se cotejaron títulos. Tampoco se establece relación propietarios y propiedades, que permitiría comprender la existencia de alguna forma de acumulación.

Por otro lado, se explicita que se censaron en la zona 411 "casas de propiedad" ( 4 de azotea y 407 de adobe y paja) (Segundo Censo Nacional, 1895, Tomo II, p. 17). Pero para el Censo, "casa" remitía a todo edificio con entrada propia (fueran viviendas, depósitos, talleres, fábricas, iglesias). En cuanto a establecimientos agrícolas, estancias o chacras, se especificaba que todo rancho, galpón o piezas aisladas una de otra, se contarían como "una casa aparte" (Segundo Censo Nacional, 1895, Tomo III, p. X), lo que permite considerar que no todas esas "casas" eran propiedades. Se mencionaban aparte 75 propiedades agrícolas, 62 cultivadas por propietarios, 12 por arrendatarios y 1 por medianeros (Segundo Censo Nacional, 1895, Tomo III, p. 105), que posiblemente integrasen el número de 248 propietarios.

Otro problema es que este conteo no aporta una distinción entre las variadas dimensiones de las propiedades de la zona. Este punto es importante y requiere seguir profundizándose dado que, como señalan algunos herederos de las "familias fundadoras", la riqueza se basaba en la posesión de tierras, ya que la circulación de dinero era escasa en todas las capas sociales (Entrevista con descendiente de familia fundadora, julio de 2013). En este sentido, difieren las nuevas parcelas de Colalao, que rondaban las 6 u 8 ha (Fandos, 2007) de otras como la de Pilar Aráoz (luego Comunidad Aráoz Hermanos) con 7.400 ha, o de El Bañado, con 30.000 ha. Por su parte, el territorio de la comunidad de Amaicha mantuvo, hasta 1970, 52.817 ha. 
Por otro lado, si tomamos como certero el número de 248 propietarios, este debe ponerse en relación con las 459 familias censadas en todo Tafí II, formadas por 3015 individuos y con un promedio de 5,8\% de individuos por familia Amaicha y Colalao, que en la sección de Tafí II asciende a casi 8 . En base a estos números, podría inferirse que sólo el $54 \%$ de esas familias eran propietarias, mientras que el otro $46 \%$ serían arrendatarios. Si bien esto es una aproximación y requiere ser revisada, algunos datos sueltos confirman que aunque se hubiera extendido el acceso a la propiedad individual en algunos sectores, el porcentaje de arrenderos continuaba siendo alto. A modo de ejemplo, El Bañado contaba con una población de 250 habitantes entre Anjuana, Quilmes y "La Estancia" (o "la Sala"), donde funcionaba una escuela para 58 alumnos, más otra que se estaba creando en Quilmes. Distintas entrevistas recogidas en el trabajo de campo indican que muy pocos de esos arrenderos consiguieron que los subsiguientes dueños les vendieran algunas parcelas, y esto recién a mediados del siglo XX.

Por último, debe decirse que la lógica propietaria como parámetro de pertenencia social fue un criterio reproducido desde la colonia y por quienes accedieron tardíamente a la tierra por distintas vías durante el siglo XIX, que se transformaron también en parte de la "élite" local, clasificación que no implica que se tratase de un grupo homogéneo y sin tensiones (Mata, 2000; Medina, 2002). Pero, además, muchos documentos muestran que fueron los miembros de dichas elites ${ }^{8}$ quienes ocuparon funciones públicas de justicia, administración departamental, policía y educación, lo que significó la legitimación del poder de esos sectores, que pasaron a ser enclaves territoriales del Estado en esos parajes lejanos. Estos cargos, a veces ejercidos simultáneamente por la misma persona, implicaban la comunicación con el gobierno provincial, al que se elevaban variados asuntos de la esfera pública como el servicio eclesiástico, el funcionamiento educativo o el enrolamiento militar, convirtiendo a estos sujetos en capilares locales del control institucional. Medina (2003) ha indicado que los grupos de poder local manipularían los recursos del Estado para perpetuar su posición económica y social y extender su propio poder, aprovechando la alternancia entre un Estado presente y uno ausente, que intervenía poco y desde una externalidad manifiesta. En este sentido, coincido con Melossi (1992) en que la misma participación de los agentes en la estructura estatal está orientada por la prosecución de sus propios y diversos intereses. Plantear la externalidad y alternancia de la presencia del Estado implica considerarlo como una entidad independiente, cuando los propietarios, al cumplir funciones públicas, eran ellos mismos el Estado, la expresión local de su estructura (Tolosa, 2018).

\section{LA ECONOMÍA DE LOS SUBALTERNOS}

Lo antes planteado permite comprender ciertas generalidades del contexto. Ahora bien, ¿es posible acercarse de algún modo a los sectores subalternizados de la zona? Este acercamiento es metodológicamente complejo justamente porque no se refleja en documentos oficiales. Por ello he intentado una aproximación desde las ocupaciones registradas en los Censos de 1869 y 1895 en el distrito de Encalilla -posteriormente Tafí IIque permitan identificar la posición de esos sujetos.

Respecto del Censo de 1869, hay que aclarar que presenta numerosas dificultades, por ser el primero en su género. ${ }^{9} \mathrm{Su}$ información es aproximada y los errores de toma y proyección fueron denunciados ya en esa época. Una primera dificultad es que parte del Censo utilizó como base un padrón de 1857 que contenía errores que se arrastraron, como aumentos inexistentes en las cifras de población que respondían a los intereses políticos de cada provincia (Groussac et al., 1882, p. 271). Otra, que la participación pudo estar condicionada por la percepción de la gente sobre las encuestas:

\footnotetext{
Es evidente que los comisarios del censo han sido mistificados, en muchas partes, por los habitantes de la campaña (...) lo que hace cinco o seis años aconteció con el censo escolar: casi todos los mayores de edad ganaron el monte, temiendo que "se tratase de enrolamiento", y los Comisarios no hallaron en los ranchos sino mujeres y niños. De ahí, el no distribuir á los “mayores de 14 años" en varones y mujeres comprendieron lo grotesco de un cuadro en que Tucumán apareciera como un pueblo de amazonas, con una ínfima minoría de hombres (Groussac et al., 1882, p. 270).
} 
En lo que a su lectura refiere, las dificultades principales son que las cantidades varían entre los libretos censales y la publicación de los resultados, y que al no haber criterios categoriales unificados, estos se aplican según la elección de cada empadronador. Por otro lado, entre el censo de 1869 y el de 1895 se produjeron recategorizaciones de los núcleos, debido a un problema de difícil resolución: cómo determinar una "población urbana o de pueblo, en contraposición a la rural o de campaña" (Censo Nacional, 1895, p. XXIII). En ese momento, los dispersos poblados podían pasar a convertirse en villas o ciudades en pocos años, lo que hacía inaplicable la definición por cantidad de población. La arbitraria solución fue presentar como centros urbanos todos los que fueran "así considerados por las respectivas comisiones" (Censo Nacional, 1895, p. XXIV). Esto explica por qué el vecino distrito catamarqueño de Santa María, que en 1869 se dividía en un sector urbano (Santa María Pueblo, San José, Fuerte Quemado y Chañarpunco) y un área rural (Quebrada, El Cajón, Andalguala, parte de Santa María y de San José), pasó en 1895 a dividirse en más sectores (Chañarpunco, Fuerte Quemado, Loroguasi, Quebrada, Recreo, San José, Cajón y Santa María); pero todo el conjunto pasó a ser considerado rural, a pesar de superar los 6.500 habitantes. Contrariamente, la Encalilla rural de 1869 pasó a dividirse en el poblado rural de Amaicha, con 771 habitantes, un sector rural más amplio, denominado Tafí II, con 1212 habitantes, mientras que Colalao del Valle se dividió en un sector rural de 687 habitantes y otro urbano, con sólo 350 (Censo Nacional, 1895, p. 524). Ahora bien, si los criterios quedaban en manos de las comisiones locales, es posible contemplar la intervención de sus propios intereses político-económicos en la categorización. Y si esto se pone en relación con los ya señalados discursos sobre la potencia productiva de Colalao, podría inferirse que su categorización "urbana" pudo haber sido parte del constructo de ese espacio "prometedor". En la siguiente Tabla (3) es posible observar el pronunciado aumento demográfico ocurrido entre ambos Censos para el distrito de Tafí II:

TABLA 3

Variación de la población en los distritos de Encalilla/Tafí II y Santa María

\begin{tabular}{|c|c|c|c|c|c|c|c|}
\hline Departamento & Categoría & $\mathbf{1 8 6 9}$ & Departamento & Categoría & \multicolumn{2}{|c|}{$\mathbf{1 8 9 5}$} & Variación \\
\hline \multirow{3}{*}{ Encalilla } & \multirow{3}{*}{ Rural } & \multirow{3}{*}{$\mathbf{1 . 4 6 1}$} & Amaicha & Rural & 771 & & \\
& & Colalao & Urbano & 345 & & \\
& & & Colalao & Rural & 687 & \multirow{3}{*}{$\mathbf{3 . 0 1 5}$} & $\mathbf{+ 1 . 5 5 4}$ \\
& & & Tafí II & Rural & 1.212 & & \\
\hline
\end{tabular}

Fuente: Elaboración propia a partir de los Censos Nacionales de 1869 y 1895, AGN, Censo Nacional de 1869 y 1895.

En cuanto a la composición poblacional por edades, en 1869 se calculó un $53.52 \%$ (783 niños hasta 15 años sobre un total de 1.463) para Encalilla. En 1895 se implementó un nuevo corte etario a los 14 años y las proporciones se reducen un poco, siendo de 49.52 \% (1493 niños sobre un total de 3015) para Tafí II. Por otro lado, el nivel de alfabetización era prácticamente nulo en 1869 (sólo $7.72 \%$ ), pero se incrementa en 1895 llegando a un total de $21.72 \%$ de alfabetizados/escolarizados mayores de 6 años. 
Los gráficos ocupacionales se basan en los libretos manuscritos del Censo de 1869 para Encalilla, y en los de 1895 para y Tafí II. Estos se han elaborado sobre la población potencialmente activa, teniendo en cuenta que la mayoría de las personas declaran ocupación a partir de los 14 años y que los longevos mantienen generalmente su actividad. Para 1869, la población ocupada es de 622 personas, contra 841 sin ocupación declarada (42,50\%), la mayoría de ellos niños pequeños y mujeres, que contribuían en sus economías familiares. Para 1895, la población potencialmente activa asciende a 1.653, sobre un total de 3.015 (54,82\%).

Debe aclararse que en el análisis de datos ocupacionales se repite el problema de los criterios disímiles de los empadronadores (y posiblemente también las adscripciones personales de los propios sujetos). $\mathrm{He}$ intentado respetar las categorías originales de los documentos, pero he establecido grupos entre agricultoreslabradores, así como entre peones, jornaleros y trabajadores (categoría que aparece sólo en un censista que no registra ninguna de las otras dos, por lo cual infiero que se trata de jornaleros). También debe decirse que estas categorías también difieren entre las cédulas censales y las publicaciones de los Censos; en la publicación de 1869 , por ejemplo, el conteo de profesiones para la provincia incorpora tanto "agricultores" como "labradores"; mientras que se agrupan “jornaleros, peones y gañones”. Por su parte, el de 1895 estima agricultores pero no labradores, aunque la categoría aparece en las cédulas manuscritas.

Lo mismo sucede con los peones, que en la publicación se nombran como "jornaleros, personal de fatiga que no tiene trabajo fijo". Un problema importante ocurre con la categoría criadores, que no aparece en ninguna de ambas publicaciones pero abunda en los libretos. En 1869 podría inferirse que están incluidos en "estancieros y hacendados", dadas las cifras de este rubro fuera del distrito capital; pero no hemos podido identificar cómo se incluyen en 1895, donde aparecen los rubros "hacendados" (propietarios rurales), pastores y estancieros; ni cómo se relacionan exactamente estas categorías con la propiedad de los animales o de la tierra.

FIGURA 2

Gráfico Ocupacional construido con datos de los libretos censales del Distrito de Encalilla

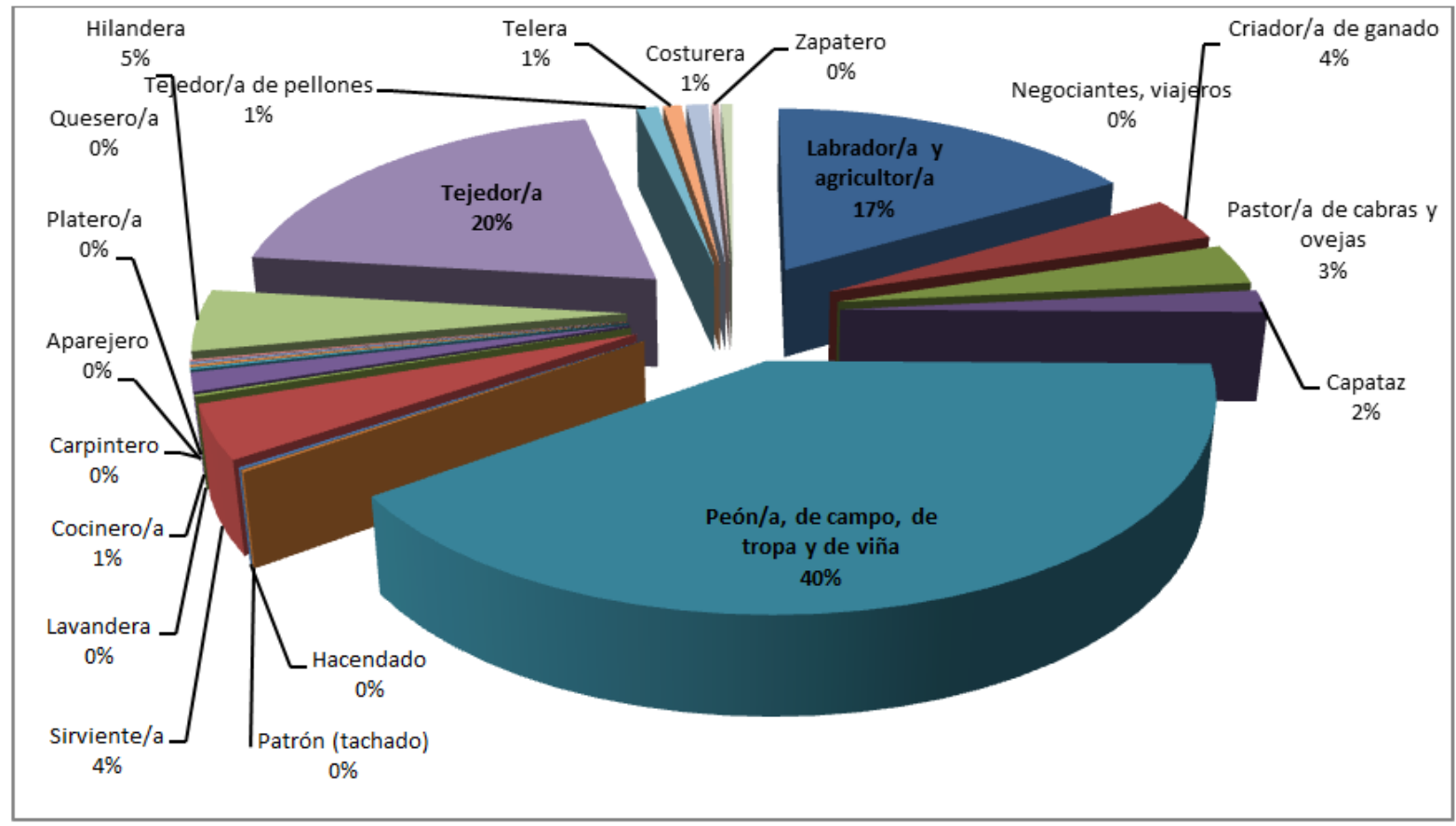

Fuente: Elaboración propia a partir del Censo Nacional de 1869, Libretos manuscritos, Encalilla, Tucumán. 
FIGURA 3

\section{Gráfico ocupacional construido con datos de los libretos censales del Distrito de Tafí II}

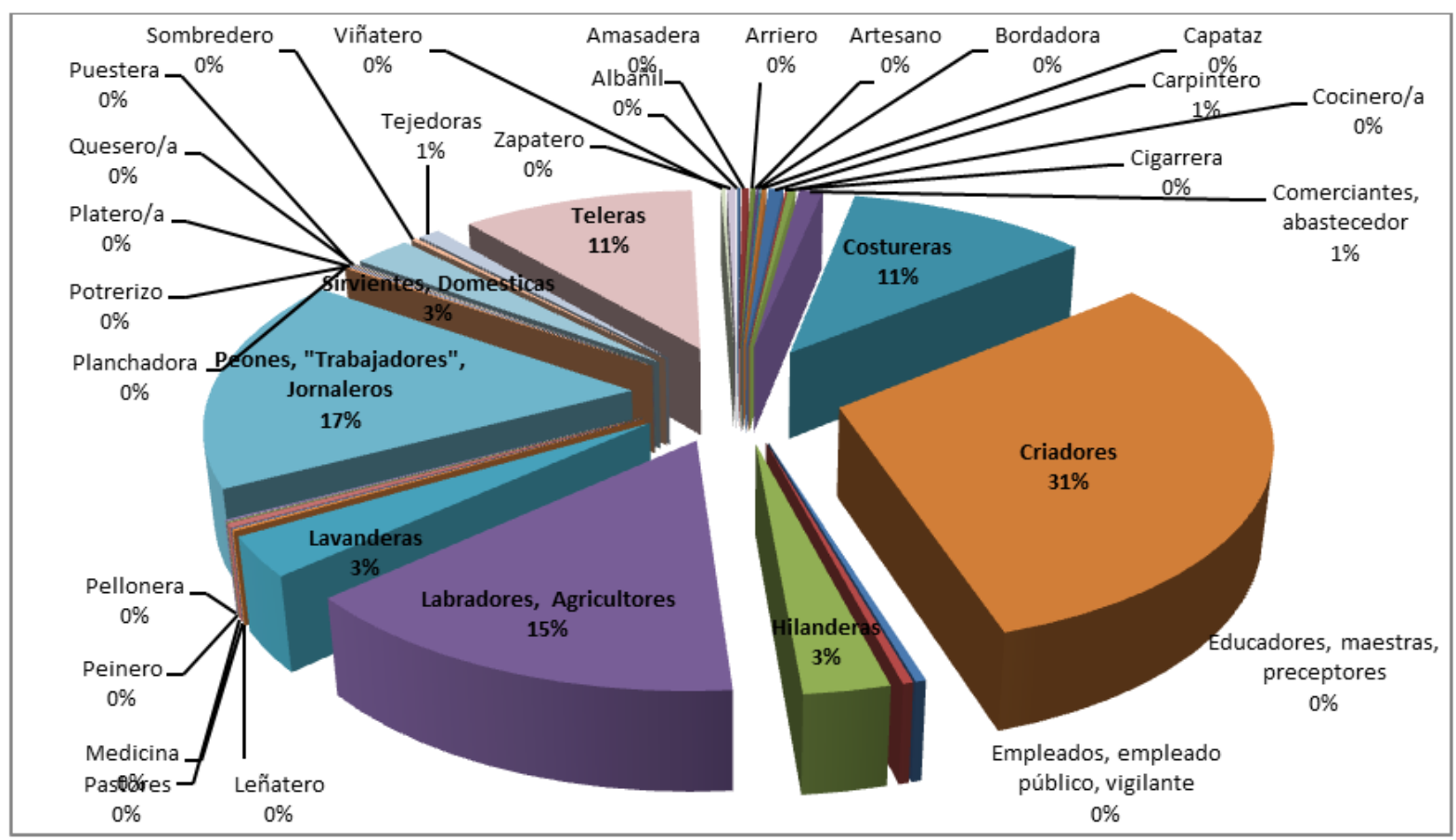

Fuente: Censo Nacional de 1895. Libretos manuscritos, Tafí II, Tucumán.

Los gráficos permiten ver una variación -numérica y proporcional- en las actividades, que además deben vincularse con la duplicación de la población. En primer lugar, se observa una mayor diversificación de actividades, posiblemente en relación con la creciente urbanización de los poblados. En 1869 ciertas actividades sólo podían encontrarse en la zona urbana de Santa María, pero eran inexistentes en el espacio rural, como por ejemplo productores de manufacturas como cigarros, sombreros, amasadoras o artesanos; servicios de medicina, o peluquería; cargos en educación, empleos públicos o de policía. También hay un leve incremento del sector comerciante y en oficios constructivos como la albañilería y la carpintería.

Un aparte merecen las actividades realizadas por mujeres, donde los porcentajes varían bastante de un Censo al otro. Por ejemplo, las costureras pasan de constituir un escaso $1 \%$ en 1869 a un $11 \%$ en 1895 , números que se repiten para las teleras. Pero al mismo tiempo las tejedoras, que en 1869 constituían el 21 $\%$ de la ocupación femenina (incluyendo pelloneras), y por lo tanto una parte importante de las economías familiares, se reducen ahora al $1 \%$, y las hilanderas del $5 \%$ al $3 \%$. Si se tiene en cuenta que las tareas del propio hogar no se consideraban "trabajo" en estos Censos, es posible que estos números indiquen la forma de ganarse la vida de estas mujeres. Por lo tanto, ¿es posible que estas variaciones correspondan a un cambio de las actividades tradicionales hacia otras, ahora más requeridas por un incipiente "mercado" laboral?

Sobre el personal doméstico, aparece una leve disminución (de $4 \%$ a $3 \%$ ) en el sector de las "sirvientas", pero aumenta el de lavanderas, de $0 \%$ a 3\%. Estos trabajos (como el de los peones) indican mayor dependencia económica de un sector social respecto de otro. 
Respecto de los trabajos rurales, aparece un gran aumento del $4 \%$ al $31 \%$ en el sector de los criadores, lo que coincide con el aumento en el número de cabezas que colocaba a Tafí entre los primeros puestos en la producción provincial. Como mencioné, es difícil saber si la categoría se relaciona con la propiedad de los animales. Por otro lado, en el caso de que fueran dueños, tampoco es posible saber cuáles de ellos poseían sus parcelas y cuáles pagaban cánones de pastura a otros propietarios para sostener su hacienda. No obstante, el incremento en la actividad entre ambos censos hace preguntarse si esto estuvo asociado al aumento poblacional o a algún tipo de movilidad social ascendente, en el marco de una economía en desarrollo.

Al mismo tiempo, el porcentaje de labradores y agricultores se mantiene estable; con lo cual las proyecciones de ampliación productiva hacia el sector agrícola de las Memorias parecen no estarse cumpliendo. Más aun, a la luz de los datos del Censo, es evidente un reforzamiento de la actividad ganadera, tradicional en la zona. Los labradores ${ }^{10}$ descienden de un $17 \%$ en 1869 a un $15 \%$ en 1895 , con una población mucho mayor. Tampoco en este caso es posible estimar qué parte de este conjunto corresponde a agricultores libres con parcelas propias y cuánto a arrendatarios instalados en fincas ajenas; tal como mencionamos, mientras que el Censo de 1869 no consigna datos sobre la propiedad de la tierra, el conteo del de 1895 no permite establecer precisiones sobre el tipo de propiedades que incluye. No obstante, los datos parciales permiten ver que, más allá de un mayor acceso a la tierra en algunos sectores, los arrenderos seguían constituyendo un gran sector del campesinado local, que si bien producían para su propia subsistencia o para intercambio a pequeña escala, cumplían pagos y obligaciones laborales a sus patrones, lo que limitaba su libertad y sus posibilidades de ascenso social.

Por último, he agrupado en el gráfico a los peones, peonas, jornaleros (y las variantes que aparecen en los libretos, como peón de campo, de tropa, de viña). Cabe destacar que la categoría peona aparece en gran número, demostrando la importancia del trabajo femenino, aunque es difícil determinar si las tareas realizadas eran sustancialmente diferentes a las de los varones. Para 1869, en Encalilla el sector sumaba el 40 $\%$ de la población ocupada; sin embargo, es notoria la reducción de la peonada para 1895, donde suman sólo el $17 \%$. ¿Es posible adjudicar esta reducción a una emigración hacia el sector cañero en crecimiento? Para el siglo XX se sabe con certeza que los vallistas trabajaban estacionariamente en la zafra, pero de este momento la información es casi nula. ¿O por el contrario, hubo algún traspaso de este sector en el aumento producido en el de los criadores? Me inclino más a creen en la primera opción, si tenemos en cuenta que las posibilidades de ascenso en este sector eran más escasas que en las anteriores.

Medina (2003) agrupa a los arrenderos junto con la peonada formando la "clase baja" del valle. Sin embargo, es posible que las situaciones de explotación dentro de ese conjunto fueran diversas. La ausencia de datos impide estimar, por ejemplo, qué proporción de los "peones" eran parte de núcleos familiares cuya subsistencia se sostenía en el sistema de arriendo. Tampoco es posible saber, en ese caso, si los jornales se pagaban enteros o eran descontados totalmente o en parte de las obligaciones de trabajo. Es posible que las combinaciones fueran variadas, lo que lleva a recordar lo sostenido por Meillassoux (1998 [1975]) sobre cómo las familias campesinas han reproducido su fuerza productiva para ser vendida por jornales mínimos, incluso de manera intermitente o estacional. Por otro lado, también existían individuos con un patrón de asentamiento móvil por carecer de hogar fijo, sobre todo solteros. ${ }^{11}$ 


\section{Palabras finales}

En este trabajo he descripto las características contextuales de la zona de los valles Calchaquíes tucumanos a fines del siglo XIX. En primer lugar, me he centrado en tres importante fuentes provinciales de la época que muestran inicialmente una concepción de la zona como marginal en términos productivos, en fuerte contraste con el llano tucumano -en plena expansión de la industria azucarera-, percepción que va cambiando con el tiempo, hacia el planteo de mejores posibilidades.

También he planteado la existencia de distintas formas de propiedad, desarrolladas a partir de procesos históricos diversos, sobre un territorio originariamente indígena. Así, para fines del siglo XIX es posible señalar la convivencia entre formas de propiedad comunal como en el caso de Amaicha, procesos de fraccionamiento - como el de parte de Colalao del Valle- y continuidad de grandes fincas que prosiguieron con el sistema de arriendo. Al mismo tiempo, he señalado que los sectores propietarios ejercieron las funciones públicas, lo que implica un acceso diferencial a la prosecución de sus propios intereses y la exclusión de los sectores subalternos del acceso a sus derechos.

Respecto de estos, tanto las fuentes como los relatos de los comuneros ancianos sobre sus antecesores permiten conocer que gran parte de los mismos eran arrendatarios y cumplían obligaciones para con sus patrones. Por su parte, los datos de los censos confirman que un gran porcentaje de la población estaba dedicado a tareas de poca calificación. Pero me gustaría cotejar, para concluir, la afirmación que hacen los indígenas actuales sobre la pertenencia de sus antecesores al sector más subalternizado y sobre su condición indígena. Para ello tomaré como ejemplo la relación entre las categorías de peón e indio que aparecen en las publicaciones de arqueólogos y expedicionarios de fines del XIX, usadas para referir a aquellos que vivían y trabajaban en las fincas -y que fueron también parte de la mano de obra de las excavaciones-.

Los investigadores mencionan a estos sujetos de la zona como indios, destacando incluso que muchos de ellos son "puros" (Brackebusch, 1966 [1891]; Ten Kate, 1893; Ambrosetti, 1896; Lange, 1892; Bruch, 1910; Quiroga, 1926; entre otros). En una región supuestamente vaciada de indígenas, esto ha sido señalado como una paradoja sintomática de la "invención" de una nación homogénea que escondía la heterogeneidad de las poblaciones que la integraban (Rodríguez, 2008b) donde la noción de mestizaje se utilizaba como sinónimo de desaparición del indígena. En el marco de invisibilización general destinado a la creación de una Argentina blanca (Briones, 1998) los valles Calchaquíes otorgaban el argumento histórico de su "vaciamiento" en el siglo XVII y de la "extinción" de sus indígenas (cuyo paradigma fueron justamente los Quilmes), negando a quienes escaparon, fueron encomendados o volvieron; a lo que se sumó la desaparición de la condición jurídica tributaria de "indio" durante la República. Para fines del siglo XIX, lo indígena se colocaba en el pasado de la población:

mezcla de los conquistadores españoles con los indijenas: esto es, con las tribus calchaquies, conocidas antes por los nombres de quilmes, calianes, andalgalás, guafures, tinogastas, fiambalás, etc., todas de raza quichua. Al presente la raza india ha desaparecido casi del todo, como ha desaparecido el uso de su lengua (Censo Nacional, 1869, pp. 454, 492).

Pero además de explicitar la existencia de los indios en contraste con la estadística oficial, los relatos de los investigadores exhiben el rol de estos indios en el sistema socioeconómico local. En este marco, el uso de la categoría peón ${ }^{12}$ para definirlos puede verse como otro mecanismo de solapamiento. En consonancia con el funcionamiento del "mestizaje" (donde se impone el componente "blanco" sobre el "indio" pero este no desaparece, ya que sirve a las construcciones de alteridad y desigualdad) la categoría laboral peón oculta la indigenidad, pero esta continúa activa en el trato cotidiano, actualizando día a día el aspecto racial implícito en la subalternización. Así, arrenderos, peones y sirvientes de la zona siguieron siendo "indios" en el desarrollo de sus tareas, aunque se los acriollara en las blanqueadas estadísticas oficiales. 
La mutua concordancia entre las categorías indio y peón en estos escritos -que en muchos casos incluso se usan juntas para describir a las personas- permite dar cuenta de su mutua funcionalidad en la legitimación de la expoliación de recursos y de la fuerza de trabajo indígena local. Esto se inscribe en un marco general de explotación basado en la apropiación territorial y reducción de los indígenas a arrendatarios o a mano de obra, repetido en distintos puntos (Mariátegui, 2009 [1928]; Quijano, 2000; Madrazo, 1994). Para este caso, la relación establecida entre la subalternidad y la indigenidad respecto de los peones, se corresponde con la percepción que los actuales comuneros tienen sobre sus antecesores, especialmente en aquellos sectores donde la prevalencia de grandes fincas conservó el sistema de arriendo y patronazgo (definido como terratenientismo) e incluso sobre ellos mismos, en el caso de los ancianos. En distintas entrevistas se recuerda al uso del término indio como insulto o peyorativo por parte de los patrones o de las maestras.

De este modo, si bien la complejidad y los matices observados para el área indican una variedad de formas y relaciones socioeconómicas sobre las que es necesario continuar indagando, el acercamiento a las condiciones existentes a fines del siglo XIX que hemos planteado en este trabajo permite establecer correspondencias con los relatos actuales y colabora con el proceso de reconstrucción de la historia larga de comunidad.

\section{REFERENCIAS BIBLIOGRÁFICAS}

S/A (1916).Álbum General de la Provincia de Tucumán. Primer Centenario de la Independencia Argentina. 1816-1916. Tucumán: Comisión Oficial del Centenario.

Ambrosetti, J. B. (1895). La industria vinícola en Salta. Boletin del Departamento Nacional de Agricultura. Órgano del departamento de tierras, colonias y agricultura, 19(20), 561-574.

Ambrosetti, J. B. (1896). Costumbres y supersticiones en los valles Calchaquíes (Provincia de Salta). Anales de la SCA, $41,41-85$.

Ambrosettti, J. B. (1904). El bronce en la región calchaquí. Anales del Museo Nacional, 11, 163-314.

Avellaneda, N. (1865). Estudios sobre leyes de Tierra Pública de sobre el problema de las tierras públicas. Buenos Aires: Imprenta del Siglo.

Balán, J. (1976). Migraciones, mano de obra y formación de un proletariado rural en Tucumán, Argentina, 1870-1914. Demografía y economía. 10(2), 201-234.

Barbieri, M. y Garrido, H. (2008). Cólera, condiciones de existencia y tensiones sociales, Tucumán de fines del siglo XIX. En V. García Acosta (coord.), Historia y desastres en América Latina, Vol. III. Recuperado de: http://ww w.desenredando.org/public/libros/2008/hyd/Historia_y_Desastres_VolumenIII.pdf

Boixadós, R. (2011). El fin de las guerras calchaquíes. La desnaturalización de la nación yocavil a La Rioja (1667). Corpus. Archivos Virtuales de la alteridad americana, 1(1). Recuperado de: http://ppct.caicyt.gov.ar/index.php /corpus

Brackebusch, L. (1966 [1891]). Viajes en las Cordilleras de la República Argentina. Boletín de la Academia Nacional de Ciencias, 44 (1-4), 197-223.

Bravo, M. C. (1999). El campesinado tucumano: de labradores a cañeros. De la diversificación agraria hacia el monocultivo cañero. En J. Gelman, J. C. Garavaglia y B. Zeberio (comps.), Expansión capitalista y transformaciones regionales. Buenos Aires: La Colmena-IEHS.

Briones, C. (1998) La alteridad del cuarto mundo. Una construcción antropológica de la diferencia. Buenos Aires: Del Sol.

Bruch, C. (1910) “Antropometría de cuatro naturales del noroeste argentino". Congreso Cientifico Internacional Americano, Buenos Aires.

Bruno, P. (2017) Las derivas de Paul Groussac como articulador cultural entre exposiciones internacionales, celebraciones y eventos públicos, 1882-1911. Anuario IEHS, 32(1), 111-134

Campi, D. (1991). Captación y retención de mano de obra por endeudamiento, el caso de Tucumán en la segunda mitad del siglo XIX. Ciclos en la historia, la economía y la sociedad, I(1), 149-167.

Campi, D. (1996) “Auge azucarero, coacción y mercado de trabajo. Tucumán (Argentina) en el último cuarto del siglo XIX”. En A. Malpica (Ed.) Agua, trabajo y azúcar. Granada: Diputación Provincial. 
Campi, D. y Lagos, M. (1995). “Auge azucarero y mercado de trabajo en el Noroeste argentino (1850-1930)”. Circuitos mercantiles y mercados en Latinoamérica, México: UNAM.

Carlón, F. (2007). "La reducción "Exaltación de la Cruz de los indios Quilmes": un caso de relozalizacion étnica en Pampa a fines del siglo XVII". Mundo Agrario, 8(15). Recuperado de: http://www.scielo.org.ar

Censo Nacional (1869). Libretas manuscritas, Encalilla. Recuperado de: https://familysearch.org/search/collection/ 1462401

Censo Nacional (1895). Libretas manuscritas, Tafí II. Recuperado de: https://familysearch.org/search/ collection/1410078

Comunidad India Quilmes (CIQ) (2006). Los Quilmes contamos nuestra historia. San Miguel de Tucumán, Ministerio de Desarrollo Social, Instituto Nacional de Asuntos Indígenas y Proyecto Desarrollo de Comunidades Indígenas.

Consejo Federal de Inversiones (CFI) (1974). Diagnóstico expeditivo de la situación jurídica, económica y social de las áreas en situación de comunidades indivisas de la provincia de Tucumán.

De la Fuente, D. G. (1872). $1^{\circ}$ Censo de la República Argentina. Verificado en los días 15, 16 y 17 de setiembre de 1869. Bajo la dirección de Diego G. de la Fuente, superintendente del Censo. Buenos Aires: Imprenta del Porvenir.

Fandos, C. (2007). "Estructura y transferencia de la propiedad comunal de Colalao y Tolombón (provincia de Tucumán) en la segunda mitad del siglo XIX”. Mundo Agrario. Revista de estudios rurales, 7(14). Recuperado de: http://www.mundoagrario.unlp.edu.ar

Figueroa Román, M. y Mulet, F. (1949). Planificación Jurídica de Amaicha del Valle. Instituto de Sociografía, Colegio Libre de Estudios Superiores de Tucumán.

Girbal-Blacha, N. (1991) "Estado, modernización azucarera y comportamiento empresario en la Argentina, 1876-1914". En D. Campi, (comp.) Estudios sobre la historia de la industria azucarera argentina. Jujuy; UNJU: 17-59.

Giudicelli, C. (2007). "Encasillar la frontera. Clasificaciones coloniales y disciplinamiento del espacio en el área diaguito-calchaquí (S. XVI-XVII)”, Anuario IEHS, 22, 161-212

Granillo, A. (1872). Provincia de Tucumán. Serie de artículos descriptivos y noticiosos. Tucumán: Imprenta de La Razón.

Groussac, P., Bousquet, A., Liberani, I., Terán, J. M. y Frías, J. (1882). Primera Memoria histórica y descriptiva de la Provincia de Tucumán. Buenos Aires: Imprenta M. Biedma.

Hoskold, H.D. (1894). Informe General sobre las colecciones de Minerales productos metalúrgicos y maquinaria minera. Expuestos por las diversas naciones en la Exposición Internacional de Chicago 1893. Buenos Aires: Imprenta de Obras de J.A. Berra.

Isla, A. (2002). Los usos politicos de la identidad. Indigenismo y Estado. Buenos Aires: De las Ciencias.

Lafone Quevedo, S. (1888). Londres y Catamarca. Cartas a La Nación 1883, 1884 y 1885. Buenos Aires: Editorial, Imprenta y Librería de Mayo.

Lafone Quevedo, S. (1894). Relación Histórico-descriptiva del Mineral de las Capillitas y de sus Ingenios en Andalgalá. En Provincia de Catamarca: Industria Minera y Metalúrgica. Datos suministrados por el Ingeniero de minas don Emilio Huniken por encargo del delgado especial don Adolfo E. Carranza, para la Exposición Minera y Metalúrgica de la República de Chile (pp. 51-54). Buenos Aires: Imprenta de Juan A. Alsina.

Lafone Quevedo, S. (1899). Viaje a los Menhires e Intihuatana de Tafí y Santa María en octubre de 1898.Revista del Museo de La Plata XI: 123-128.

Lagos, M. (1992). Conformación del mercado laboral en la etapa del despegue de los ingenios azucareros jujeños (1880-1920). En D. Campi (comp.), Estudios sobre la historia de la industria azucarera argentina II. Tucumán, UNJU-UNT. 
Lange, G. (1892). Las ruinas de la Fortaleza del Pucará. Anales del Museo de La Plata, III, 3-16.

López, C. y Bascary, A. M. (1998). Pueblos indios de Colalao y Tolombón: identidad colectiva y articulación étnica y social (siglos XVII-XIX). Humanitas, 27, 71-112.

Lorandi, A. M. (2000). Las rebeliones indígenas. En E. Tandeter (dir.), Nueva Historia Argentina. Tomo II. La Sociedad Colonial (pp. 285-330). Buenos Aires: Sudamericana.

Lorandi, A. M. y Boixadós, R. (1987-88). Etnohistoria de los Valles Calchaquíes. Runa, XVII-XVIII, 263-420.

Madrazo, G. (1994). Historia de un despojo: el indigenado del noroeste argentino y su transformación campesina. ANDES, Antropología e Historia, 6, 127-156.

Mariátegui, J. C. (2009 [1928]). 7 ensayos de interpretación de la realidad peruana. Buenos Aires: Capital Intelectual.

Mata, S. (1999). Valorización de las propiedades agrarias y dinámica de las transacciones de tierras en Salta a fines del período colonial. Boletin del instituto de Historia Argentina y Americana "Dr. Emilio Ravignani", 19, 7-33 serie

Mata, S. (2000). Tierra y poder en Salta. El noroeste argentino en visperas de la independencia. Sevilla: Diputación de Sevilla.

Medina, M. C. (2002). Landless women, powerful men. Land, gender and identity in NW Argentina (Colalao - El Pichao, 1850-1910). Göteborg: Göteborg University.

Medina, M.C. (2003). Narrativas y representaciones de la identidad: las clases sociales en los valles calchaquíes a fines del siglo XIX. GOTARC. Serie C, Arkeologiska skrifter 54 Etnologiska studier, 46.

Meillassoux, C. (1998 [1975]). Mujeres, graneros y capitales. México: Siglo XXI.

Meister, A., Petruzzi, S. y Élida, S. (1963). Tradicionalismo y cambo social. Estudio de área en el Valle de Santa María. Rosario: FFyL-UNL.

Melossi, D. (1992). El Estado del control social. México: Siglo XXI.

Paz, G. (2004). Las bases agrarias de la dominación de la elite: tenencia de tierras y sociedad en Jujuy a mediados del siglo XIX. Anuario IHES, 19.

Palermo, M. y Boixadós, R. (1991). Transformaciones en una comunidad desnaturalizada: los Quilmes, del valle calchaquí a Buenos Aires. Anuario del IEHS, VI, 13-42.

Palomeque, S. (2000). El mundo indígena, siglos XVI-XVIII. En E. Tandeter (dir.), Nueva Historia Argentina, La sociedad colonial [Tomo II] (pp. 87-144). Buenos Aires: Sudamericana.

Quijano, A. (2000). “Colonialidad del poder, eurocentrismo y América Latina”. En E. Lander (ed.) Colonialidad del saber y eurocentrismo. Buenos Aires, UNESCO-CLACSO: 201-246.

Quiroga, A. (1926). Calchaqui, Buenos Aires, Rosso y Cía.

Reyes Gajardo, C. (1965). "Estudios sobre el valle de Tafí y de Amaicha del Valle. Datos Históricos y culturales.”(Ms)

Rodríguez, L. (2008a). Después de las desnaturalizaciones: transformaciones socio-económicas y étnicas al sur del Valle Calchaqui. Santa Maria, fines del siglo XVII-fines del siglo VIII. Buenos Aires: Antropofagia.

Rodríguez, L. (2008b). ¿Mestizos o indios puros? El valle Calchaquí y los primeros antropólogos. Avá, 13, 77- 98.

Rodríguez, L. (2009). Los usos del sistema judicial, la retórica y la violencia en torno a un reclamo sobre tierras comunales. Amaicha del Valle, siglo XIX. Runa, 30(2), 135-150.

Rutledge, I. (1987). Cambio agrario e integración. Tucumán: CICSO -ESCIRA.

Sánchez Román, J. (2008). Integración territorial y especialización económica. Tucumán y el estado nacional, 1850-1880. Jornadas de Historia Politica, Mendoza.

Sosa, J. (2015). Amaycha, la identidad persistente: Desterritorialización y reterritorialización de una comunidad tricentenaria (XVIII a XXI) (Tesis Doctoral inédita). Facultad de Filosofía y Letras, Universidad de Buenos Aires, Buenos Aires, Argentina. 
Steiman, A. L. (2013). Estado y comunidad: disputas y articulaciones en el espacio local a partir de la fundación de la Villa de Amaicha del Valle, Tucumán. Fines del siglo XIX a mediados del XX. Memoria americana, 21(2).

Ten Kate, H. (1893). Rapport sommaire sur une excursion archéologique dans las provinces de Catamarca, de Tucumán et de Salta. Revista del Museo de la Plata, V, 331-348.

Tolosa, S. (2018). Los Antiguos y el estado. Historia de la construcción material del patrimonio arqueológico, sur del valle Calchaqui (1877-2008). (Tesis doctoral inédita) Facultad de Filosofía y Letras, Universidad de Buenos Aires, Buenos Aires, Argentina.

Tolosa, S. (2019). "Organización indígena, territorio, estado y violencia en torno al Primer Parlamento Indígena de los Valles Calchaquíes, 1973”. (En prensa).

Unión de los Pueblos de la Nación Diaguita de Tucumán (UNPDT). (2015). Del I al IV Parlamento Regional Indigena Juan Calchaqui. 4 décadas de construcción y resistencia. Tucumán: Caja Popular de Ahorros.

Zerda de Cainzo, H. (1972). Amaicha en el Valle calchaquí. Notas para su historia. Aportes para la historia de Tucumán (pp. 29-55). Tucumán: Universidad Católica.

\section{Notas}

1 “Memoria de la finca El Bañado". Agrimensor Arturo L. Bello. Septiembre de 1911." En Expediente Catastral Bañado de Quilmes, "Ruinas de Quilmes", Tafí del Valle (F. 48).

2 Los efectos de la pobreza se transformaron en una amenaza, especialmente por las epidemias de viruela y cólera de fines del siglo XIX. La última (1886) se propagó inmediatamente a través de fuentes hídricas, facilitada por el clima del llano, la debilidad orgánica de los trabajadores, las precarias condiciones de vida y la falta de higiene, afectando especialmente a los sectores subalternos. Se declararon 4.787 muertes entre 1886/1887, aunque se calcula que en la campaña muchas fueron ocultadas por temor al aislamiento sanitario y a la medicina (Barbieri y Garrido, 2008).

3 De entre estos, Julián Ruiz de Huidobro adquirió el Potrero del Rincón, que heredó a su hijo Diego Martín Ruiz de Huidobro y que luego pasó por compra a José Manuel Silva. A su muerte en 1848, la propiedad fue dividida. Potrero Grande, que comprendía las estancias de La Banda y Las Carreras, fue heredado por sus hijas Manuela y Carmen de Chenaut. A su vez, Nicolás Valerio Laguna heredó a sus sobrinos Mercedes de Zavalía y Fernando de Zavalía el de Carapunco, formándose la estancia Las Tacanas, donde el presbítero Estratón Colombres (1819-1901) inauguró la iglesia en 1895.

4 En 1911 componían la comunidad de Amaicha: "[F o G]. Velárdez, M. Fabián, M. Rodríguez, F. Lera, Fco. Velárdez, Fco. Ayala, D. Balderrama, R. Mamani, B. Pastrana, J. Rueda, S. Medina, J. Mamani, C. G. de Velárdez, J. B. Mamani, P. Lera, W. Fabián, V. Balderrama, S. Velárdez, J. Sazo, N. Nieva, J. Ayala, M. Valero, B. Lazo, E. Balderrama, C. Herrera, R. Nieva, M. Herrera, P. Balderrama, S. P. de Balderrama, C. P. de Ayala, L. Ch. de Balderrama, E. Quiroga, C. Velárdez, E. Guerra, T. Guerra, l. Olivares, J. González, O. Olivares, B. Velárdez, O. Quiroga, M. Morales, P. Fregenal, [O. o A.] Balderrama, G. Balderrama, N. Cortés, N. Lera, A. Chocobar, S. Ríos, Bonifacio Nieva." En "Duplicado del Deslinde de Mensura y Amojonamiento por los rumos N y $S$ del fundo denominado El Bañado, Propiedad del Señor Francisco Urrestarazu ubicado en el segundo Distrito del Departamento de Tafí. Agrimensor Arturo L. Bello. Septiembre de 1911.” (F.34). Expediente Catastral Bañado de Quilmes, "Ruinas de Quilmes”, Tafí del Valle.

5 Las últimas categorizaciones de "indios" para los valles son en 1786. Se contaban 535 indios varones mayores de 18 años (tributarios). De estos, 100 eran arrendatarios, 73 agregados, 15 conchabados, 22 residentes, 54 "vivos" y 11 sin datos (Mata, 2001, citado en Medina, 2002).

6 El 20 de noviembre de 1875 Cristina López de Brancheri (viuda de José de Aramburu) testó a favor de su hija adoptiva Mercedes Llovet de Chavarría (escritura del 24/11/1889). En 1907 la heredan sus hijos José Antonio, Silverio, Manuel, Ricardo y Dolores Chavarría, que venden la propiedad a Javier Rivas el 2 de agosto de 1907 (escritura del 05/02/1908) y este a su vez a Francisco Urrestarazu y Carlos Serrey (escritura del 21/12/1910). En 1921, Urrestarazu vuelve a vender su $50 \%$ a Rivas. El 30 de junio de 1925, Baltazar Chico compra la propiedad a Serrey y a Rivas y a su muerte, en 1929 la heredan María Teodosia Monasterio de Chico, Francisco Baltazar, María Teodosia, María Dolores y Luis Antonio Chico.

7 "Duplicado del Deslinde de Mensura y Amojonamiento por los rumbos N y S del fundo denominado El Bañado, Propiedad del Señor Francisco Urrestazu ubicado en el segundo Distrito del Departamento de Tafí. Agrimensor Arturo L. Bello. Septiembre de 1911" (F.33-34). Expediente Catastral Bañado de Quilmes, "Ruinas de Quilmes", Tafí del Valle.

8 Las comunicaciones con el gobierno provincial permiten identificar en los cargos los nombres de propietarios locales. A modo de ejemplos: propuesta de vecinos de Tafí para la construcción de un camino a capital, firmada por Emilio 
Sal, Ángel Esteves, Benjamín Zavaleta y Justiniano Frías, Manuel Avellaneda y Clemente Zavaleta (AHT, Sección Administrativa 134, Tomo I, F. 162-163); pedido del comisario Wellington Navarro para que se reconstruya la escuela de Colalao (AHT, Sección Administrativa Vol.131, Tomo II, 1877, F.397); reclamo del Juez de Paz Clemente Zavaleta por el cierre de una escuela en Tafí (AHT, Sección Administrativa 135, Tomo I, 1878, F.319-320); nota del comisario J. P. Aráoz destinando ingresos a la construcción de una escuela (AHT, Sección Administrativa Vol.159, Tomo IV, 1883, F.397 y reverso); formación de la Comisión Vecinal para repartir ayuda a inundados, compuesta por el Comisario Susano Araoz, el Juez de Paz Belisario Morales y el cura Basilio Baruzzo (AHT, Sección Administrativa 142, Tomo I, 1880, F.140 y 212); entre muchos otros.

9 Anteriormente, para Encalilla y Colalao, Julián Navarro - propietario y comandante militar- habría realizado un primer censo en 1845, con un resultado de 156 viviendas y una población de 782 personas: 85 varones mayores de 14 años, 247 menores y 450 mujeres de todas las edades (AHT, Sección Administrativa 62, 1845, Fs. 32-34). En 1857 la población había aumentado a 957 personas.

$10 \mathrm{Paz}$ (2004) indica que labrador era una categoría ocupacional empleada en varias regiones de la Argentina del XIX para señalar al trabajador agrícola, por oposición al criador o pastor, términos vinculados a la ganadería. La caracterización del labrador supone variaciones según la región; en Tucumán define a pobladores rurales, pequeños propietarios o arrendatarios que practicaban agricultura familiar y constituían un alto porcentaje de la población de campaña (Bravo, 1999).

11 Estos individuos eran asociados al problema de la vagancia y de la fuga, ocasionando muchos conflictos. La relación entre el peonaje y ciertos delitos era común a toda la provincia. En 1881, de 2.623 ingresados a la Policía, 1.255 eran jornaleros; frente a entre 120 y 170 labradores, sirvientes y albañiles y 148 "sin profesión”. 1.024 causas correspondían a ebriedad, 419 a fuga de sus patrones y en menor medida robo, vagancia o pendencias (entre 110 y 200) (Groussac et al., 1882, pp. 695-698).

12 El uso de esta categoría no es exclusivo de esta zona; lo que se analiza aquí es su caracterización en este marco específico. 